\title{
Construção e validação de cartilha para prevenção do excesso ponderal em adolescentes
}

Construction and validation of a booklet to prevent overweight in adolescents Elaboración y validación de cartilla para prevención del exceso ponderal en adolescentes

Jayne Ramos Araújo Moura'

Kadija Cristina Barbosa da Silva ${ }^{1}$

Aparecida do Espirito Santo de Holanda Rocha ${ }^{1}$

Sinderlândia Domingas dos Santos ${ }^{1}$

Thais Raiane da Silva Amorim ${ }^{1}$

Ana Roberta Vilarouca da Silva ${ }^{1}$

\section{Descritores}

Sobrepeso; Obesidade; Educação em saúde; Tecnologia educacional; Adolescente

Keywords

Overweight; Obesity; Health education; Educational technology; Adolescent

Descriptores Sobrepeso; Obesidad; Educación en salud; Tecnología educacional; Adolescente

Submetido 23 de Junho de 2018

Aceito

2 de Maio de 2019

\section{Autor correspondente}

Jayne Ramos Araújo Moura

https://orcid.org/0000-0002-7311-7782

E-mail: jayneramoura@gmail.com

\section{DOI}

http://dx.doi.org/10.1590/1982-

0194201900051

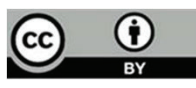

\section{Resumo}

Objetivo: Desenvolver e validar uma cartilha educativa para prevenção do excesso de peso em adolescentes.

Métodos: Estudo metodológico desenvolvido em quatro etapas: diagnóstico situacional; levantamento bibliográfico; elaboração da cartilha e validação do material por especialistas no assunto, 15 juízes (conteúdo e design) e representantes do público-alvo, 36 adolescentes escolares. Para a coleta de dados, foram utilizados três questionários distintos, de acordo com o foco de avaliação de cada grupo de participantes. Os dados foram analisados por meio da estatística descritiva, avaliação do Índice de Validade de Conteúdo, sendo considerado item validado 0 que apresentar valor igual ou superior a 0,78, e nivel de concordância, apresentando validação o item que obtiver concordância mínima de $75 \%$ nas respostas positivas. As observações dos juízes foram analisadas e, quando necessário, a cartilha foi modificada.

Resultados: 0 índice de validade de conteúdo médio foi de 0,87 e 0,96 por meio das análises dos juízes de conteúdo e de design, respectivamente. As principais sugestões tecidas por eles versavam acerca da substituição ou troca de termos e adequação de textos. Em relação ao público-alvo, participaram adolescentes de 14 a 18 anos. 0 nível de concordância nas respostas positivas dadas pelos adolescentes foi de $82 \%$ e as principais sugestões estiveram associadas às cores e ilustrações da cartilha

Conclusão: A cartilha mostrou-se válida e confiável para utilização como tecnologia educativa em intervenções com adolescentes que visem a torná-los agentes de mudança e protagonistas do cuidado com seu corpo.

\section{Abstract}

Objective: To develop and validate an educational booklet to prevent overweight in adolescents.

Methods: Methodological study developed in four stages: situational diagnosis; bibliographic survey; booklet preparation and material validation by experts, 15 judges (content and design) and representatives of the target public, 36 schoolchildren. For the data collection, three different questionnaires were used according to the focus of assessment of each group of participants. The data were analyzed through descriptive statistics, Content Validity Index assessment. It was considered a valid item the one that presented a value equal or higher than 0.78 , and agreement level, presenting validation the item that obtained a minimum agreement of $75 \%$ in the positive responses. The judges' observations were analyzed and, when necessary, the booklet was modified.

Results: The average Content Validity Index was 0.87 and 0.96 by the judges' content and design analysis, respectively. The main suggestions made by them were about the substitution or exchange of terms and suitability of texts. The target audience was adolescents aged 14 to 18 years. The agreement level in the positive responses given by adolescents was $82 \%$ and the main suggestions were associated with the booklet's colors and illustrations.

Conclusion: The booklet proved to be valid and reliable for use as educational technology in interventions with adolescents aimed at making them agents of change and protagonists of care for their body.

\section{Resumen}

Objetivo: crear y validar una cartilla educativa para prevención del exceso de peso en adolescentes.

Métodos: estudio metodológico desarrollado en cuatro etapas: diagnóstico situacional, recopilación bibliográfica, elaboración de cartilla y validación del material por especialistas del asunto, 15 jueces (contenido y diseño) y representantes del público destinatario, 36 adolescentes escolares. Para la recolección de datos, se utilizaron tres cuestionarios diferentes, de acuerdo con el foco de evaluación de cada grupo de participantes. Los datos fueron analizados por medio de la estadística descriptiva, análisis del Índice de Validez de Contenido, considerando como ítem válido aquel que presente valor igual o superior a 0,78 y nivel de concordancia, con validación del ítem que obtenga concordancia mínima de $75 \%$ en las respuestas positivas. Las observaciones de los jueces fueron analizadas y, cuando se consideró necesario, la cartilla fue modificada. Resultados: el índice de validez de contenido promedio fue de 0,87 y 0,96 por medio del análisis de los jueces de contenido y de diseño, respectivamente. Las principales sugerencias por ellos formuladas fueron referentes a la substitución o cambio de términos y adecuación de los textos. Con relación al público destinatario, participaron adolescentes de 14 a 18 años. El nivel de concordancia de las respuestas positivas dadas por los adolescentes fue del $82 \%$ y las principales sugerencias estaban relacionadas con los colores e ilustraciones de la cartilla.

Conclusión: la cartilla demostró ser válida y confiable para ser utilizada como tecnología educativa en intervenciones con adolescentes con el objetivo de tornarlos agentes de cambio y protagonistas del cuidado de su cuerpo.

\section{Como citar:}

Moura JR, Silva KC, Rocha AE, Santos SD, Amorim TR, Silva AR. Construção e validação de cartilha para prevenção do excesso ponderal em adolescentes. Acta Paul Enferm. 2019;32(4):365-73. 


\section{Introdução}

Atualmente, a epidemia de sobrepeso e obesidade configura-se como um grave problema de saúde pública no Brasil e em todo mundo. Dados da Organização Mundial da Saúde (OMS) indicam que, em 2014, 1,9 bilhóes de adultos com 18 anos ou mais estavam acima do peso e, destes, mais de 600 milhóes eram obesos. Destaca-se que, naquele mesmo ano, 41 milhóes de crianças, com idade menor que cinco anos, estavam com sobrepeso ou obesas. ${ }^{(1)}$

Ademais, o excesso de peso está associado ao surgimento de dislipidemias, aumento da pressão arterial, representando causa fisiopatológica mais prevalente da resistência insulínica. ${ }^{(2)}$ Naqueles com excesso de peso, pelo menos um fator de risco secundário é encontrado, além disso, quanto maior o índice de massa corporal (IMC), maiores são as chances de alteração em parâmetros bioquímicos, como triglicerídeos e HDL-c. ${ }^{(3,4)}$

É importante destacar que tanto sobrepeso como obesidade são problemas que podem ser prevenidos com adoção de hábitos saudáveis de vida. É sabido, ainda, que a adolescência é o período no qual vários hábitos e comportamentos são estabelecidos, incorporados e, possivelmente, perpetuados na idade adulta; sendo, dessa maneira, imprescindível incentivar o adolescente a se tornar sujeito ativo do seu cuidado, através de estratégias de educação que visem à promoção da saúde, à prevenção de agravos e ao autocuidado. ${ }^{(5,6)}$

A educação em saúde é uma importante ferramenta para a socialização de conhecimento, de promoção da saúde e de prevenção de doenças, com vistas à construção e incorporação de práticas que visam a mudanças de comportamentos prejudiciais à saúde por meio do empowerment dos sujeitos, incluindo modelos de intervenção participativos e considerando o saber de todos os envolvidos. ${ }^{(5,7)}$ Estas ações, quando permeadas através de impressos, como manuais, folhetos, folders e cartilhas, configuram-se como instrumentos viáveis para informação e sensibilização de crianças e adolescentes, permitindo aos jovens e à sua família uma leitura posterior, servindo como guia em casos de dúvidas e auxiliando nas tomadas de decisão cotidianas. ${ }^{(8,9)}$
Levando em consideração a clara e imprescindível necessidade do desenvolvimento de estratégias de enfrentamento dessa problemática, e que os enfermeiros merecem destaque por desenvolverem açóes de caráter educativo em diferentes contextos de cuidado à criança e ao adolescente, é preciso que sejam idealizados instrumentos para auxílio no desenvolvimento dessas atividades.

Diante disso, e considerando que após busca em bases de dados nacionais utilizando os descritores "Tecnologia", "Sobrepeso" e "Obesidade", não foram localizados estudos que relatassem a criação e validação de cartilhas voltadas para a prevenção do excesso de peso no público adolescente. Assim, este trabalho teve como objetivo desenvolver e validar uma cartilha educativa para prevenção do excesso de peso em adolescentes. Espera-se que a cartilha configure-se como instrumento de apoio ao desenvolvimento de estratégias educativas realizadas por profissionais da saúde e/ou da educação, como também, seja largamente utilizada nos cenários promotores de saúde, como as Unidades Básicas de Saúde e as escolas.

\section{Métodos}

Trata-se de uma pesquisa metodológica, que tem como foco o desenvolvimento, a avaliação e o aperfeiçoamento de instrumentos e de estratégias metodológicas, ${ }^{(10)}$ realizada no período de maio de 2017 a fevereiro de 2018.

A construção da cartilha foi fundamentada no diagnóstico situacional junto a 30 adolescentes, de 14 a 17 anos, de uma escola pública do município de Picos/PI, através do desenvolvimento de dois grupos focais conduzidos pela pesquisadora. A amostra foi escolhida por conveniência e foram excluídos os adolescentes acompanhados por profissionais de nutrição, pois estes poderiam apresentar conhecimento sobre a temática acima da média dos demais adolescentes, somando 10 participantes em cada grupo.

Os grupos foram conduzidos na própria escola, em sala de aula reservada, em horário distinto das aulas, com duração média de 30 minutos. $\mathrm{O}$ grupo 
foi conduzido por meio da seguinte questão: "Como o excesso de peso pode influenciar minha vida?". Os pontos mais frequentes de questionamento foram registrados pela pesquisadora responsável.

Após a realização do diagnóstico situacional, foi iniciado o levantamento bibliográfico. Nessa fase, foram avaliadas as recomendações do Ministério da Saúde, além de artigos científicos, relacionadas à prevenção do excesso de peso em adolescentes. A confecção do texto da cartilha levou em consideração a faixa etária dos adolescentes, o resultado do diagnóstico situacional e o levantamento bibliográfico. Em sequência, com auxílio de designer gráfico, foi elaborada a arte, por meio da confecção de figuras e formatação, configuração e diagramação das páginas, concluindo a fase de construção do material.

A cartilha, denominada "Psiu, quais as consequências do excesso de peso? Saiba como se prevenir!”, foi validada, quanto ao conteúdo e à aparência, por juízes especialistas nas áreas de interesse, distribuídos em duas categorias de avaliação: nove juízes de conteúdo (com experiência metodológica e técnica relativa ao conteúdo da tecnologia) e seis juízes com experiência profissional em design e marketing. ${ }^{(11,12)}$

Em relação aos juízes especialistas, estes foram selecionados por meio da amostragem do tipo bolade-neve, amostragem por conveniência bastante utilizada quando a população é composta por pessoas com características difíceis de serem encontradas, ${ }^{(10)}$ conforme critérios de seleção, como formação acadêmica, atuação profissional (ensino, pesquisa, extensão), curso de atualização e produção científica, para os juízes de conteúdo; ${ }^{(13,14)}$ e experiência comprovada de, no mínimo, um ano, para os juízes de design, em alguma das seguintes áreas: em comunicação digital e off-line; assessoria em designer, comunicação, marketing digital; analista de marketing digital; criação; web designer; publicidade e propaganda.

Um convite foi enviado via e-mail para os juízes e aqueles que aceitavam participar da pesquisa tinham acesso online, por meio da ferramenta Google Forms ${ }^{\oplus}$ ao: Termo de Consentimento Livre e Esclarecido, cartilha, e protocolo de validaçáo do instrumento. O prazo para retorno do contato foi de 15 dias, podendo ser concedido novo prazo de mais 10 dias.
Após as consideraçóes dos juízes, foram feitos os ajustes necessários no material, para prosseguir com a validação do material educativo pelo público-alvo. Os adolescentes foram captados em escolas públicas estaduais do município de Picos, segundo os seguintes critérios de inclusão: estar matriculado e frequentar regularmente a escola; ter disponibilidade de 20 a 30 minutos para participar da leitura da cartilha e responder ao questionário de avaliação. Participaram do processo avaliativo 36 adolescentes. ${ }^{(15)}$

A validação da cartilha pelo público alvo ocorreu na escola, mediante entrevista individual com a criança, em sala reservada, após a leitura da cartilha impressa, com a aplicação do instrumento de coleta de dados. Vale salientar que os adolescentes que participaram do processo de validação não foram os mesmos que foram incluídos na fase do diagnóstico situacional.

O questionário de avaliação encaminhado aos juízes de conteúdo foi adaptado ${ }^{(16)}$ e estruturado em: I - informações referentes à área de atuação e estudo; II - escala tipo Likert, com níveis variando de 1 = inadequado, 2 = parcialmente adequado, 3 = adequado, 4 - totalmente adequado, sobre itens relacionados aos objetivos; estrutura e apresentação; e relevância. $\mathrm{O}$ questionário para a validação com os juízes de design foi o Suitability Assessment of Materials (SAM). ${ }^{(17)}$ Foram investigados quanto à atuação profissional e, em seguida, constaram questôes com respostas de escala tipo Likert, com níveis variando de 1 = inadequado, 2 = parcialmente adequado, 3 = adequado, 4 = totalmente adequado, quanto aos itens referentes à cartilha educativa. Para a análise, foi empregado o Índice de Validade de Conteúdo (IVC) para validação do instrumento, sendo considerado item validado o que apresentar valor igual ou superior a $0,78 .^{(10,13)}$

O cálculo do IVC foi feito a partir da somatória das respostas " 3 " e " 4 " de cada juiz em cada item do questionário, com a somatória dividida pelo número total de respostas. Os itens que receberam pontuação "1" ou " 2 " foram revisados ou eliminados, e validados quando apresentaram sugestôes para alteraçóes. ${ }^{(13)}$

O questionário de avaliação destinado ao público-alvo foi dividido em duas partes, a primeira, contendo informações de identificação e, a segunda, representando a área de avaliação da cartilha. $\mathrm{O}$ 
instrumento educativo foi avaliado de acordo com a adequação dos itens: "Sim", "Não" ou "Em Parte". Os itens foram considerados validados quando apresentarem concordância mínima de $75 \%$ nas respostas positivas. Os itens com índice de concordância menor foram considerados passíveis de alteração. ${ }^{(13)}$

O estudo foi submetido à avaliação pelo Comitê de Ética em Pesquisa (CEP) da Universidade Federal do Piauí (UFPI), por meio da Plataforma Brasil, obtendo parecer de aprovação sob $N^{\circ}$ 853.499. Foram respeitados os preceitos éticos referentes à Resolução 4662012 do Conselho Nacional de Saúde-CNS.

\section{Resultados}

Os principais pontos abordados pelos adolescentes no diagnóstico situacional giravam em torno de como se determina o excesso de peso e na ideia de o adoecimento não existir durante esta fase da vida. Em seguida, com a realização do levantamento bibliográfico, o conteúdo foi selecionado e organizado cronologicamente. Foram utilizadas publicaçôes veiculadas pelo Ministério da Saúde do Brasil, Organização Mundial da Saúde e artigos científicos, sendo estas adicionadas ao fim da cartilha, na seção Referências. As informaçóes foram apresentadas de maneira a interagir com o adolescente, na voz ativa.

No processo de validação de conteúdo, participaram nove juízes conteúdo, cuja idade variou de 26 a 43 anos, com prevalência da faixa etária menor que 35 anos (55,6\%); sexo feminino (77,8\%); formação em enfermagem (77,8\%); com atuação na docência (77,8\%); titulação doutorado (55,6\%). A área de estudo mais frequente foi "Hábitos alimentares" $(77,8 \%)$, seguida por "Saúde de adolescentes" $(55,6 \%)$.

De acordo com o questionário de avaliação, os juízes julgaram a cartilha de acordo com o disposto na tabela 1 .

Diante dos itens de avaliação (objetivos, estrutura e apresentação, relevância) dispostos na tabela 1 , a cartilha foi validada com êxito pelos juízes de conteúdo, apresentando IVC global de 0,88. Quanto aos objetivos, nenhum item foi julgado inadequa-
Tabela 1. Avaliação dos juízes de conteúdo quanto aos objetivos, estrutura e apresentação e relevância da cartilha

\begin{tabular}{|c|c|c|c|c|c|}
\hline & \multicolumn{4}{|c|}{ Avaliação } & \multirow[b]{2}{*}{ IVC } \\
\hline & Inadequado & $\begin{array}{c}\text { Parcialmente } \\
\text { adequado }\end{array}$ & Adequado & $\begin{array}{c}\text { Totalmente } \\
\text { adequado }\end{array}$ & \\
\hline Objetivos & & & & & 0,81 \\
\hline $\begin{array}{l}\text { São coerentes com as } \\
\text { necessidades dos jovens } \\
\text { em relação à prevenção } \\
\text { do excesso de peso }\end{array}$ & - & - & 4 & 5 & 1,0 \\
\hline $\begin{array}{l}\text { Promove mudança de } \\
\text { comportamento e atitude }\end{array}$ & - & 5 & 2 & 2 & 0,44 \\
\hline $\begin{array}{l}\text { Pode circular no meu } \\
\text { científico }\end{array}$ & - & - & 3 & 6 & 1,0 \\
\hline $\begin{array}{l}\text { Estrutura e } \\
\text { apresentação }\end{array}$ & & & & & 0,86 \\
\hline $\begin{array}{l}0 \text { material educativo } \\
\text { é apropriado para } \\
\text { orientação de jovens } \\
\text { em relação à prevenção } \\
\text { do excesso de peso }\end{array}$ & - & 1 & 2 & 6 & 0,89 \\
\hline $\begin{array}{l}\text { As mensagens são } \\
\text { apresentadas de } \\
\text { maneira clara e objetiva }\end{array}$ & - & 1 & 4 & 4 & 0,89 \\
\hline $\begin{array}{l}\text { As informações } \\
\text { apresentadas são } \\
\text { cientificamente corretas }\end{array}$ & - & 4 & 2 & 3 & 0,56 \\
\hline $\begin{array}{l}\text { Há uma sequência } \\
\text { lógica do conteúdo } \\
\text { proposto }\end{array}$ & - & 1 & 1 & 7 & 0,89 \\
\hline $\begin{array}{l}0 \text { material está } \\
\text { adequado ao nível } \\
\text { sociocultural do } \\
\text { público-alvo }\end{array}$ & - & 2 & 3 & 4 & 0,78 \\
\hline $\begin{array}{l}\text { As informações são } \\
\text { bem estruturadas em } \\
\text { concordância e ortografia }\end{array}$ & - & - & 4 & 5 & 1,0 \\
\hline $\begin{array}{l}0 \text { estilo de redação } \\
\text { corresponde ao nível } \\
\text { de conhecimento do } \\
\text { público-alvo }\end{array}$ & - & 1 & 4 & 4 & 0,89 \\
\hline $\begin{array}{l}\text { Informações da } \\
\text { capa, contracapa, } \\
\text { agradecimentos e } \\
\text { apresentação são } \\
\text { coerentes }\end{array}$ & - & 2 & 3 & 4 & 0,78 \\
\hline $\begin{array}{l}\text { As ilustrações } \\
\text { são expressivas e } \\
\text { suficientes }\end{array}$ & - & 1 & 2 & 6 & 0,89 \\
\hline $\begin{array}{l}0 \text { número de páginas } \\
\text { está adequado }\end{array}$ & - & - & 2 & 7 & 1,0 \\
\hline $\begin{array}{l}0 \text { tamanho do título } \\
\text { e dos tópicos está } \\
\text { adequado }\end{array}$ & - & - & 2 & 7 & 1,0 \\
\hline $\begin{array}{l}\text { Não existem } \\
\text { informações } \\
\text { desnecessárias }\end{array}$ & - & 2 & 2 & 5 & 0,78 \\
\hline Relevância & & & & & 1,0 \\
\hline $\begin{array}{l}\text { Os temas retratam } \\
\text { aspectos chaves que } \\
\text { devem ser reforçados }\end{array}$ & - & - & 4 & 5 & 1,0 \\
\hline $\begin{array}{l}0 \text { material propõe à } \\
\text { população adquirir } \\
\text { conhecimento quanto ao } \\
\text { manejo da prevenção do } \\
\text { excesso de peso }\end{array}$ & - & - & 4 & 5 & 1,0 \\
\hline $\begin{array}{l}\text { Está adequado para ser } \\
\text { utilizado por qualquer } \\
\text { profissional da área da } \\
\text { saúde em atividades } \\
\text { educativas }\end{array}$ & - & - & 4 & 5 & 1,0 \\
\hline
\end{tabular}

IVC - Índice de Validade de Conteúdo 
do, sendo a cartilha validada, neste quesito, com IVC igual a 0,81 . No entanto, o objetivo "Promove mudança de comportamento e atitude", quando avaliado individualmente, apresentou IVC $=0,44$. Apesar dos juízes julgarem o objetivo referido como parcialmente adequado, não foram sugeridas alteraçôes, somente teceram comentários sobre a avaliação do próprio item, enfatizando que apenas a distribuição das cartilhas não, necessariamente, iria promover mudança de comportamento e atitude.

Com relação à sua estrutura e apresentação, é possível observar que nenhum item foi julgado como inadequado. O IVC $(0,86)$ foi suficiente para validaçáo da cartilha quanto à estrutura e apresentação. Ao analisar cada item individualmente, o IVC variou de 0,56 a 1,0 , sendo o quesito "As informaçóes apresentadas são cientificamente corretas" o único que apresentou IVC abaixo de 0,78, necessitando de alteraçóes. Os juízes fizeram sugestóes pontuais a respeito, principalmente, de alguns termos que foram substituídos, e/ou explicados no texto, acatando-se todas as sugestóes realizadas por eles. No concernente à avaliação da relevância, todos os itens apresentaram IVC 1,0, conferindo validação para cada um deles.

Seguindo o processo de avaliaçáo do material, a cartilha foi apreciada por um grupo de profissionais que observaram questôes técnicas no material, especialmente as referentes ao design, layout, adequação das ilustraçóes e do material. Dos seis que participaram do processo de validação, a maioria era do sexo masculino $(66,7 \%)$, com menos de 35 anos (66,7\%), atuantes na área de Design $(77,8 \%)$, da cidade de Picos-PI (83,3\%).

No concernente à avaliação, observando cada domínio de análise, o IVC variou de 0,87 a 1,0 e IVC global de 0,96 , conferindo validação da cartilha pelos juízes de design e marketing. Na grande maioria dos itens, o IVC apresentou valoração máxima $(1,0)$ (Tabela 2). As principais sugestóes desse grupo de avaliadores versavam entre a adequação de termos e as expressóes de difícil entendimento, sendo essas sugestôes acatadas no material para avaliação pelo público alvo.

Após as alteraçôes sugeridas pelos juízes, o processo de validação foi concluído junto à observação pelos
Tabela 2. Avaliação da cartilha pelos juízes de design e marketing

\begin{tabular}{|c|c|c|c|c|c|}
\hline & \multicolumn{4}{|c|}{ Avaliação } & \multirow[b]{2}{*}{ IVC } \\
\hline & Inadequado & $\begin{array}{l}\text { Parcialmente } \\
\text { adequado }\end{array}$ & Adequado & $\begin{array}{l}\text { Totalmente } \\
\text { adequado }\end{array}$ & \\
\hline Conteúdo & & & & & 1,0 \\
\hline $\begin{array}{l}0 \text { propósito está } \\
\text { evidente }\end{array}$ & - & - & 3 & 3 & 1,0 \\
\hline $\begin{array}{l}0 \text { conteúdo trata de } \\
\text { comportamentos } \\
\text { relacionados ao } \\
\text { excesso de peso }\end{array}$ & - & - & - & 6 & 1,0 \\
\hline $\begin{array}{l}0 \text { conteúdo está focado } \\
\text { no propósito }\end{array}$ & - & - & 3 & 3 & 1,0 \\
\hline $\begin{array}{l}0 \text { conteúdo destaca os } \\
\text { pontos principais }\end{array}$ & - & - & 2 & 4 & 1,0 \\
\hline $\begin{array}{l}\text { Exigência de } \\
\text { alfabetização }\end{array}$ & & & & & 0,87 \\
\hline $\begin{array}{l}0 \text { nível de leitura é } \\
\text { adequado para a } \\
\text { compreensão do leitor }\end{array}$ & - & 2 & 3 & 1 & 0,67 \\
\hline $\begin{array}{l}0 \text { vocabulário utiliza } \\
\text { palavras comuns }\end{array}$ & - & 1 & 4 & 1 & 0,83 \\
\hline $\begin{array}{l}\text { Há a contextualização } \\
\text { antes de novas } \\
\text { informações }\end{array}$ & - & - & 4 & 2 & 1,0 \\
\hline $\begin{array}{l}0 \text { aprendizado é } \\
\text { facilitado por tópicos }\end{array}$ & - & - & 3 & 3 & 1,0 \\
\hline Ilustrações & & & & & 1,0 \\
\hline $\begin{array}{l}0 \text { propósito da } \\
\text { ilustração referente ao } \\
\text { texto está claro }\end{array}$ & - & - & 2 & 4 & 1,0 \\
\hline $\begin{array}{l}\text { As figuras/ilustrações } \\
\text { são relevantes }\end{array}$ & - & - & 1 & 5 & 1,0 \\
\hline $\begin{array}{l}\text { As ilustrações têm } \\
\text { legenda }\end{array}$ & - & - & 3 & 3 & 1,0 \\
\hline $\begin{array}{l}\text { A capa atrai a atenção } \\
\text { e retrata o propósito do } \\
\text { material }\end{array}$ & - & - & 2 & 4 & 1,0 \\
\hline Layout e apresentação & & & & & 1,0 \\
\hline Característica do layout & - & - & 2 & 4 & 1,0 \\
\hline Tamanho e tipo de letra & - & - & 2 & 4 & 1,0 \\
\hline São utilizados subtítulos & - & - & 4 & 2 & 1,0 \\
\hline Motivação & & & & & 0,89 \\
\hline Utiliza a interação & - & - & 5 & 1 & 1,0 \\
\hline $\begin{array}{l}\text { As orientações são } \\
\text { específicas e dão } \\
\text { exemplos }\end{array}$ & - & - & 4 & 2 & 1,0 \\
\hline $\begin{array}{l}\text { Existe a motivação } \\
\text { à mudança de } \\
\text { comportamento }\end{array}$ & - & 2 & 4 & - & 0,67 \\
\hline Adequação cultural & & & & & 1,0 \\
\hline $\begin{array}{l}0 \text { material é } \\
\text { culturalmente adequado } \\
\text { à lógica, linguagem e } \\
\text { experiência do público- } \\
\text { alvo }\end{array}$ & - & - & 5 & 1 & 1,0 \\
\hline $\begin{array}{l}\text { Apresenta imagens e } \\
\text { exemplos adequados } \\
\text { culturalmente }\end{array}$ & - & - & 3 & 3 & 1,0 \\
\hline
\end{tabular}

IVC - Índice de Validade de Conteúdo

adolescentes, vale salientar que esse processo foi realizado para verificar a clareza, compreensão e relevância da cartilha, não se tratando de uma etapa clínica. Participaram do estudo 36 adolescentes de 14 a 18 
anos, predominaram meninos $(52,7 \%)$, da cor parda $(41,7 \%)$, com renda maior de um salário mínimo (52,6\%). O nível de concordância das respostas positivas variou de $61,1 \%$ a $100,0 \%$ entre os itens abordados, com concordância global de $82 \%$, suficiente para validar o material pelo público-alvo (Tabela 3).

Tabela 3. Validação da cartilha pelo público-alvo

\begin{tabular}{|c|c|c|c|}
\hline Conteúdos & $\begin{array}{l}\operatorname{Sim} \\
\mathrm{n}(\%)\end{array}$ & $\begin{array}{l}\text { Não } \\
\mathrm{n}(\%)\end{array}$ & $\begin{array}{c}\text { Em Parte } \\
n(\%)\end{array}$ \\
\hline 1. Apresentação literária: & $265(81,8)$ & $4(1,2)$ & $55(17)$ \\
\hline 1.1 A linguagem da cartilha é explicativa & $36(100)$ & - & - \\
\hline $\begin{array}{l}1.20 \text { material promove e encoraja a } \\
\text { prevenção do excesso de peso }\end{array}$ & $32(88,9)$ & - & $4(11,1)$ \\
\hline $\begin{array}{l}1.30 \text { vocabulário empregado é composto, } \\
\text { em sua maioria, por palavras simples e } \\
\text { comuns }\end{array}$ & $28(77,8)$ & - & $8(22,2)$ \\
\hline 1.4 A linguagem está adequada & $30(83,3)$ & $2(5,6)$ & $4(11,1)$ \\
\hline $\begin{array}{l}1.5 \text { As ideias são expressas de forma clara } \\
\text { e objetiva }\end{array}$ & $34(94,4)$ & $1(2,8)$ & $1(2,8)$ \\
\hline $\begin{array}{l}1.60 \text { texto possibilita interação } \\
\text { com orientações entre profissional e } \\
\text { adolescentes }\end{array}$ & $22(61,1)$ & - & $14(38,9)$ \\
\hline 1.70 material é de leitura agradável & $28(77,8)$ & $1(2,8)$ & $7(19,4)$ \\
\hline $\begin{array}{l}1.80 \text { material tem tamanho adequado, ou } \\
\text { seja, não é extenso nem cansativo }\end{array}$ & $28(77,8)$ & - & $8(22,2)$ \\
\hline $\begin{array}{l}1.9 \text { A cartilha, de um modo geral, é simples } \\
\text { e atrativa }\end{array}$ & $27(75,0)$ & - & $9(25,0)$ \\
\hline 2. Ilustrações: & $120(83,3)$ & $2(1,4)$ & $22(15,3)$ \\
\hline $\begin{array}{l}2.1 \text { São simples, apropriadas e de fácil } \\
\text { compreensão }\end{array}$ & $35(97,2)$ & $1(2,8)$ & - \\
\hline 2.2 São familiares para os leitores & $29(80,6)$ & - & $7(19,4)$ \\
\hline 2.3 Estão relacionadas e integradas ao texto & $29(80,9)$ & - & $7(19,4)$ \\
\hline 2.4 São autoexplicativas & $27(75,0)$ & $1(2,8)$ & $8(22,2)$ \\
\hline 3.Especificidade e Compreensão: & $88(81,5)$ & $2(3,5)$ & $18(15,0)$ \\
\hline $\begin{array}{l}3.10 \text { material propicia benefício para a } \\
\text { prevenção do excesso de peso }\end{array}$ & $34(94,4)$ & - & $2(5,6)$ \\
\hline $\begin{array}{l}3.2 \text { Não ocorre uso de sentido duplo no } \\
\text { texto }\end{array}$ & $31(86,1)$ & - & $5(13,9)$ \\
\hline $\begin{array}{l}3.30 \text { conteúdo escrito valoriza o } \\
\text { adolescente como centro das ações }\end{array}$ & $23(63,9)$ & $2(5,6)$ & $11(30,6)$ \\
\hline $\begin{array}{l}\text { 4. Legibilidade e Características de } \\
\text { Impressão: }\end{array}$ & $160(88,9)$ & $11(6,1)$ & $9(5,0)$ \\
\hline 4.1 A capa é atraente & $31(86,1)$ & $5(13,9)$ & - \\
\hline $\begin{array}{l}4.20 \text { tamanho e estilo das letras é } \\
\text { adequado }\end{array}$ & $35(97,2)$ & - & $1(2,8)$ \\
\hline 4.3 A organização do texto é adequada & $31(86,1)$ & $1(2,8)$ & $4(11,1)$ \\
\hline 4.4 A estrutura da cartilha está organizada & $32(88,9)$ & $2(5,6)$ & $2(5,6)$ \\
\hline $\begin{array}{l}4.5 \text { Existe bom contraste entre impressão } \\
\text { e papel }\end{array}$ & $31(86,1)$ & $3(8,3)$ & $2(5,6)$ \\
\hline 5. Qualidade da Informação: & $110(76,5)$ & $5(3,5)$ & $23(16,0)$ \\
\hline 5.1 A cartilha está inserida na sua cultura & $24(66,7)$ & $4(11,1)$ & $8(22,2)$ \\
\hline $\begin{array}{l}5.20 \text { material ajuda a obter o máximo de } \\
\text { benefício possível }\end{array}$ & $29(80,6)$ & $1(2,8)$ & $6(16,7)$ \\
\hline 5.30 uso da cartilha é importante & $30(83,3)$ & - & $6(16,7)$ \\
\hline $\begin{array}{l}5.4 \text { A cartilha Ihe sugeriu a agir ou pensar } \\
\text { diferente a respeito do excesso de peso }\end{array}$ & $27(75,0)$ & - & $3(8,3)$ \\
\hline
\end{tabular}

Após as adequaçóes, a cartilha, intitulada por "Psiu, quais as consequências do excesso de peso? Saiba como se prevenir!", contém 31 páginas, com dimensão de 150x200mm, papel couchê fosco 115g/ $\mathrm{m}^{2}$, com impressão em policromia, encadernação do tipo brochura, presa por dois grampos.

Após a capa, é possível visualizar a ficha catalográfica com informaçôes referentes aos autores, instituição de ensino vinculada ao desenvolvimento do material (Universidade Federal do Piauí) e diagramação. Em seguida, o material é brevemente apresentado (Figura 1).

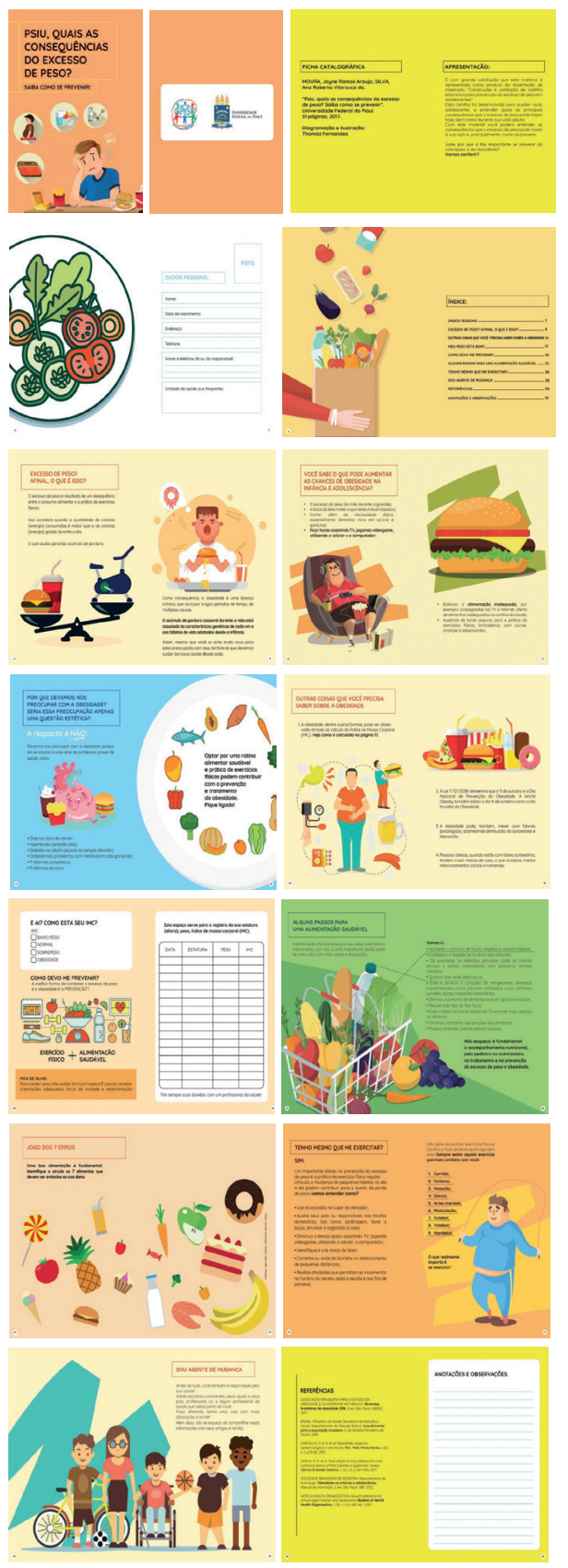

Figura 1. Versão final da cartilha 
Com o objetivo de garantir interatividade da cartilha com os adolescentes, entre os tópicos abordados no material final, existem jogos: um caça-palavras, para que relembrem/memorizem algumas consequências do excesso de peso e um jogo de sete erros referente a alimentos; além de um espaço voltado para cálculo e análise do IMC por meio de gráficos que podem ser usados por profissionais da área da saúde.

\section{Discussão}

O material elaborado diferencia-se dos demais por apresentar uma formatação leve, clara, com ilustrações remetendo ao aspecto lúdico, despertando o interesse dos adolescentes no assunto, tornando-o mais apropriado ao público; com um conteúdo objetivo, que transmite informaçóes de maneira completa, porém não exaustiva, no qual foram utilizadas palavras simples e familiares, sentenças pouco extensas, claras e de fácil entendimento. Ademais, foi validado quanto ao conteúdo e à aparência, por juízes especialistas na área, podendo ser utilizado por outros pesquisadores e contribuir no planejamento de açóes de educação em saúde condizentes com as necessidades de aprendizado do público em questão.

O processo de validação, por envolver um grupo multiprofissional, apresenta credibilidade e aspecto favorável, pois reúne diversos saberes especializados na temática abordada pelo material, sendo um parâmetro observado em outros estudo de validação. ${ }^{(18-20)}$ Ao envolver o público-alvo ainda no processo de construção da cartilha, é permitida a contribuição ativa deles na indicação dos conteúdos e na observação das suas próprias demandas. ${ }^{(13,21,22)}$

Foi necessário reconhecer que poderiam existir limitaçôes no conhecimento estabelecido no material inicialmente, e admitir que a inclusão de outros saberes é fundamental para a construção de estratégias educacionais que vão ao encontro das necessidades reais de educação em saúde. ${ }^{(23,24)}$

$\mathrm{Na}$ validação de conteúdo, identificou-se que o perfil dos juízes possuía titulação pelo menos de mestrado, sendo a maioria doutores com experiência profissional na área de saúde do adolescente e no desenvolvimento de materiais, contribuindo para a credibilidade no processo avaliativo. Diante de todos os itens de avaliação (objetivos, estrutura e apresentação, relevância), a cartilha foi validada com êxito pelos juízes de conteúdo, apresentando IVC global de 0,88.

Corroborando com estes dados, outros estudos metodológicos de desenvolvimento de tecnologias educativas também validaram seus materiais com índices estatísticos satisfatórios, a exemplo de uma investigação que validou uma cartilha para prevenção da transmissão vertical do HIV com IVC global de 0,87 pelos juízes. ${ }^{(22)}$ Já uma cartilha para alimentação saudável durante a gravidez foi validada com nível de concordância entre os juízes variando entre 0,818 e 0,954 entre os itens avaliados. ${ }^{(21)}$

A validação pelos especialistas na área de design também atingiu excelentes índices. Observando cada domínio de análise, o IVC variou de 0,87 a 1,0 e, o IVC global de 0,96. Semelhantemente, estudo realizado para validação de uma cartilha educativa sobre síndrome metabólica voltada a adolescentes apresentou validação por juízes de design elevada, com a maioria dos escores de IVC igual a $1,0 .{ }^{(18)}$ Outro estudo metodológico realizado em Belém (PA), que validou uma tecnologia educacional sobre cuidados no pós-parto, obteve IVC global de 0,81 , índice um pouco inferior ao encontrado neste estudo. ${ }^{(25)}$

Mesmo a cartilha apresentando bons índices de validação, os juízes deixaram sugestóes para o melhoramento do material. As principais sugestóes dos juízes de conteúdo estiveram relacionadas à adequação de termos, como o uso de "exercício físico" em vez de "atividade física"; cuidado na utilização do IMC como padrão de determinação do excesso de peso, mas apenas como uma das formas; adequação do gráfico de verificação do IMC em meninas; retirada de informaçôes referentes à pressão arterial e à circunferência abdominal na tabela de acompanhamento de parâmetros, pois não eram mencionadas na cartilha; foram adicionadas imagens que retratam inclusão social; reescritos textos para que ficassem mais enxutos, sem repetição de informaçóes e mais claros.

Com relação às sugestóes dos juízes de design, foram realizadas alterações de cores na capa e termos 
e expressóes técnicas que não foram explicadas na cartilha foram retirados. O processo de adaptação do material educativo às sugestóes dos juízes torna a tecnologia mais eficaz e adequada, de acordo com as sugestôes também verificadas pelo método científico, conferindo uma etapa essencial para a conclusão do material e para sua utilização durante atividades de educação em saúde. ${ }^{(22)}$

A adaptação do material educativo também é citada por outros autores como etapa essencial da validação. De modo semelhante a este estudo, outros autores realizaram adequaçóes e exclusão de informaçôes, substituição de termos, além da reformulação das ilustrações. ${ }^{(8,18)}$

Após adequaçóes, o público-alvo avaliou positivamente a cartilha educativa, considerando-a interessante, interativa, explicativa e motivadora. Essa avaliação permitiu observar que o material pode ser utilizado entre os adolescentes. Foi possível observar nível de concordância das respostas positivas igual a $82 \%$.

É importante chamar atenção para o domínio "Qualidade da Informação", que apresentou menor proporção de respostas positivas (76,5\%). Esse fato deve-se à quantidade de informaçóes apresentadas na cartilha, que pode ser minimizado com o uso da cartilha de maneira adequada, associada a açóes de educação em saúde, não apenas com a sua leitura. Com relação às sugestóes dadas pelos adolescentes, foi adicionado ao material final um jogo de sete erros com alimentos que devem ser evitados.

Vale salientar que a cartilha poderá ser utilizada como estratégia de enfrentamento do excesso ponderal em diferentes cenários, não apenas nos serviços de saúde. É preciso que escolas, famílias e comunidade estejam preparadas para propiciar a rotina de alimentação saudável e a prática de exercícios físicos. ${ }^{(26)}$

Um dos espaços privilegiados para a aplicação desta cartilha é a própria escola, pois, além de apresentar a função formal de socializar os conhecimentos produzidos pelo homem, é responsável pelo processo de humanização dos indivíduos, através da criação de condiçóes para a apropriação dos conhecimentos apresentados. ${ }^{(27)}$ Ademais, a cartilha pode ser um recurso na condução de discussóes sobre a temática, permitindo que o adolescente possa se apropriar das informaçóes apresentadas, aproximando o conhecimento em saúde do seu cotidiano por meio do protagonismo juvenil.

Muito embora o conhecimento não seja suficiente para produzir, sozinho, mudança de comportamento em relação à situação-problema, quando compartilhado de maneira concreta e contextualizado, pode provocar alteração na forma de pensar e de agir. Assim, é imprescindível que os adolescentes sejam agentes de sua própria mudança, fazendo parte das açóes implementadas para seu desenvolvimento integral e garantindo a efetividade do autocuidado para a promoção de sua saúde. ${ }^{(28)}$

Como limitação, pode-se citar a não realização da validação clínica da tecnologia, porém esta será realizada em estudo posterior.

\section{Conclusão}

Após passar por um processo rigoroso mediante avaliação por parte de juízes especialistas e por representantes do público-alvo, a cartilha construída foi validada com êxito, satisfazendo a amplitude do conteúdo referente à prevenção do excesso de peso, em uma linguagem acessível e simples. Levando em consideração as observaçôes e sugestóes provenientes do processo de validação, algumas ilustraçóes e textos passaram por modificações a fim de torná-los mais atraentes e eficazes, mesmo com o IVC e grau de concordância exibindo valores suficientes para declará-la válida e apta para sua aplicação com adolescentes. Destarte, espera-se que esta cartilha seja de fato utilizada como recurso para promoção de conhecimento e empoderamento de adolescentes frente ao excesso de peso, possibilitando a reflexão sobre seu estilo de vida atual e a adoção de medidas indicadas no material, visando a torná-los agentes de mudança e protagonistas do cuidado com seu corpo.

\section{Agradecimentos}

À Coordenação de Aperfeiçoamento de Pessoal de Nível Superior (CAPES; bolsa de mestrado para Jayne Ramos Araújo Moura). 


\section{Colaborações}

Moura JRA, Silva KCB, Rocha AESH, Santos SD, Amorim TRS e Silva ARV declaram que contribuíram com a concepção do projeto, análise e interpretação dos dados, redação do artigo, revisão crítica relevante do conteúdo intelectual e aprovação final da versão a ser publicada.

\section{Referências}

1. World Health Organization (WHO). [Obesity and overweight]. Fact Sheets [Internet]. Genève: WHO; 2016 [cited 2017 Mar. 12]. Available from: <http://www.who.int/mediacentre/factsheets/fs311/en/index.html>.

2. Medeiros CC, Ramos AT, Cardoso MAA, França IS, Cardoso AS, Gonzaga NC, et al. Insulin resistance and its association with metabolic syndrome componentes. Arq Bras Cardiol. 2011;97(5):380-9.

3. Martins RV, Bozza R, Barbosa Filho VC, Dellagrana RA, Campos W. [Comparative study of blood pressure in adolescents with different grades of nutritional status]. Motricidade. 2012; 8(S2):734-41. Portuguese.

4. Alcântara Neto OD, Silva RC, Assis AM, Pinto EJ. Factors associated with dyslipidemia in children and adolescents enrolled in public schools of Salvador, Bahia. Rev Bras Epidemiol. 2012;15(2):335-45.

5. Viero VS, Farias JM, Ferraz F, Simões PW, Martins JA, Ceretta LB. Health education with adolescents: analysis of knowledge acquisition on health topics. Esc Anna Nery. 2015;19(3):484-90.

6. Sousa ZA, Silva JG, Ferreira MA. Knowledge and practices of teenagers about health: implications for the lifestyle and self care. Esc Anna Nery. 2014;18(3):400-6.

7. Freire P. Pedagogia da autonomia: saberes necessários à prática educativa. 43a ed. São Paulo: Paz e Terra; 2011.

8. Reberte LM, Hoga LA, Gomes AL. Process of construction of an educational booklet for health promotion of pregnant women. Rev Lat Am Enfermagem. 2012;20(1)101-8.

9. Benevides JL, Coutinho JFV, Pascoal LC, Joventino ES, Martins MC Gubert FA, et al. Development and validation of educational technology for venous ulcer care. Rev Esc Enferm USP. 2016;50(2):306-12.

10. Polit DF, Beck CT. Fundamentos de Pesquisa em enfermagem: avaliação de evidências para as práticas da enfermagem. 7a ed. Porto Alegre (RS): Editora Artmed; 2011.

11. Pasquali L. Psicometria: teoria e aplicações. Brasília (DF): Editora UnB; 1997.

12. Vianna HM. Testes em Educação. São Paulo: Editora IBRASA; 1982.

13. Teles LM, Oliveira AS, Campos FC, Lima TM, Costa CC, Gomes LF, et al. Development and validating an educational booklet for childbirth companions. Rev Esc Enferm USP. 2014;48(6):977-84.
14. Freitas LV, Teles LM, Lima TM, Vieira NF, Barbosa RC, Pinheiro AK, et al. Physical examination during prenatal care: construction and validation of educational hypermedia for nursing. Acta Paul Enferm. 2012; 25(4):581-8

15. Beaton D, Bombardier C, Guillemin F, Ferraz MB. Recommendations for the Cross-cultural adaptation of the DASH \& Quick DASH Outcome Measures. Toronto: American Academy of Orthopaedic Surgeons and Institute for Work \& Health; 2007.

16. Galdino YLS. Construção e validação de cartilha educativa para 0 autocuidado com os pés de pessoas com diabetes [dissertação]. Fortaleza: Universidade Estadual do Ceará, Centro de Ciências da Saúde, Fortaleza; 2014.

17. Sousa CS, Turrini RN, Poveda VB. Translation and adaptation of the instrument "Suitability Assessment of Materials" (SAM) into portuguese. Rev Enferm UFPE on line. 2015;9(5):7854-61.

18. Moura $\mathbb{H}$, Silva AF, Rocha AE, Lima LH, Moreira TM, Silva AR. Construction and validation of educational materials for the prevention of metabolic syndrome in adolescentes. Rev Lat Am Enfermagem. 2017:25:e29342017.

19. Rabeh SA, Gonçalves MB, Cliri MH, Nogueira PC, Miyazaki MY. Construção e validação de um módulo educativo virtual para terapia tópica em feridas crônicas. Rev Enferm UERJ. 2012;20(Esp. 1):603-8.

20. Martins MC, Ferreira AM, Nascimento LA, Aires JS, Almeida PC, Ximenes LB. Influência de estratégia educativa na promoção do uso de alimentos regionais. Rev RENE. 2015;16(2):242-9

21. Oliveira SC, Lopes MV, Fernandes AF. Development and validation of an educational booklet for healthy eating during pregnancy. Rev Lat Am Enfermagem. 2014;22(4):611-20

22. Lima AC, Bezerra KC, Sousa DM, Rocha JF, Oriá MO. Development and validation of a booklet for prevention of vertical HIV transmission. Acta Paul Enferm. 2017;30(2):181-9.

23. Fernandes CS, Martins MM, Gomes BP, Gomes JA, Gonçalves LH. [Family Nursing Game: desenvolvendo um jogo de tabuleiro sobre família]. Esc Anna Nery. 2016;20(1):33-7. Portuguese.

24. Sousa CS, Turrini RN. Construct validation of educational technology for patients through the application of the Delphi technique. Acta Paul. Enferm. 2012;25(6):990-6.

25. Teixeira E, Martins TD, Miranda PO, Cabral BG, Silva BA, Rodrigues LS. Tecnologia educacional sobre cuidados no pós-parto: construção e validação. Rev Baiana Enferm. 2016;30(2):1-10.

26. Moura $\mathbb{H}$, Silva AF, Rocha AE, Lima LH, Moreira TMM Silva AR. Construction and validation of educational materials for the prevention of metabolic syndrome in adolescents. Rev Lat Am Enfermagem. 2017;25:e2934.

27. Padovani AS, Ristum M. A escola como caminho socioeducativo para adolescentes privados de liberdade. Educ Pesqui. 2013;39(4):96984.

28. Costa RF, Zeitoune RC, Queiroz MV, Gómez García Cl, Ruiz García MJ. Adolescent support networks in a health care context: the interface between health, family and education. Rev Esc Enferm USP. 2015:49(5):739-745. 